\section{REAL BROWN BREAD}

TOTWITHSTANDING the labours of chemist and physiologist, the exact composition and nutritive value of the several products obtained in milling wheat have not been thoroughly determined. That fine flour contains less nitrogen, and leaves, when burnt, less ash than biscuit flour, middlings, or any variety of bran, is well known. The percentages of starch, of the mixture of cellulose and lignose known as "fibre," and of fat, in several series of samples of mill-products, have been ascertained. Moreover, there have been made many minute analyses of the ash of wheat and of the preparations derived from it. But we are still somewhat in the dark concerning both the chemical and physiological aspects of what may justly be regarded as the central feature of the problem under discussion. For we are not sure of the nature of the nitrogen compounds which exist in the several distinct parts of the grain of wheat ; nor do we know how far the phosphates and such nitrogen compounds as may be ranked with the true albu- minoids can be digested when intimately associated with fibre. Then, too, the mechanical condition of these coarser products from the milling of wheat is of considerable moment in estimating their actual value as nutrients.

Before endeavouring to reach some conclusion as to the comparative merits of white bread, brown bread, and whole-meal bread, I will offer in as compact a form as possible the more important and incontrovertible data which must form the starting-point of the discussion.

Firstly as to variations in composition in the grain itself. These variations, chiefly affecting the percentage of nitrogen, depend upon hereditary qualities in different strains of the wheat-plant; upon climate and season; and, to some extent, but not so largely as is often stated, upon cultivation, soil, and manure. The hard translucent wheats, blés durs et glacés, of high specific gravity, about I 4 I, and, owing to their lengthened and wrinkled shape, of low weight per bushel, these wheats are rich in nitrogen. The soft opaque wheats, of less specific gravity, about $\mathrm{I} \cdot 38$, and, owing to their rounded and plump form, of high weight per bushel, these are poor in nitrogen.

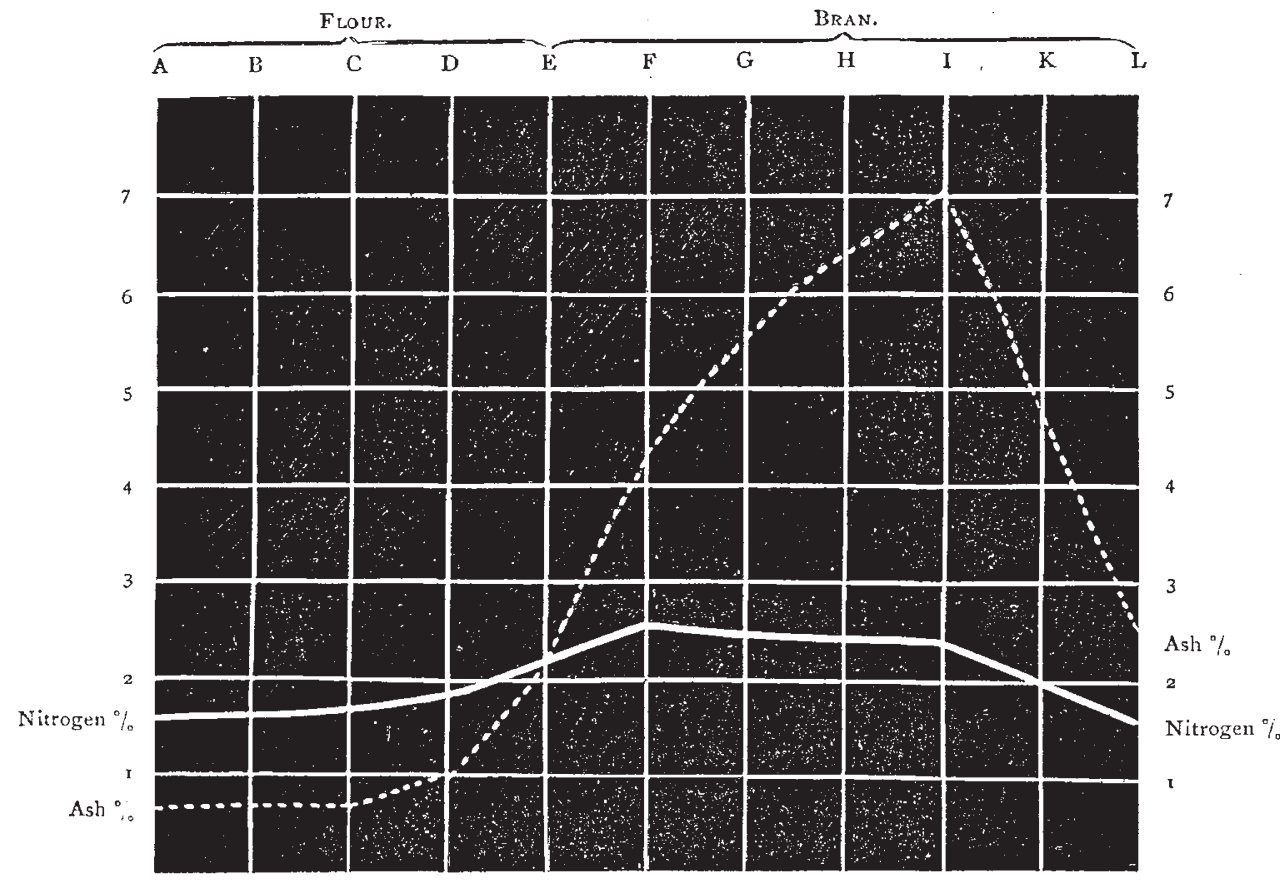

The hard wheats grown in Poland, in Southern Russia, in Italy, and in Auvergne, are used in the manufacture of macaroni, vermicelli, semolina, and pâtes d'Italie. The softer and more starchy wheats are especially appropriate for the production of fine white flour. According to the most recent analyses, the percentage of nitrogen in different varicties and samples of air-dry wheat may range from I' 3 up to 2.5 -numbers corresponding to 8.23 and 15.83 , respectively, of gluten or flesh-forming substances. But the same variety of wheat may give a grain having 3 per cent. more gluten in a bad season than when matured in a fine summer. More than this, one may select from the same field, the same plant, or even the same ear, individual grains which shall show quite as wide a variation in gluten, as that just cited. For instance, a sample of Hallett's white rough-chaffed wheat of the harvest of I 865 contained many dense and translucent horny grains having $13 \% 2$ per cent. of gluten, while the white opaque suft grains from the same sample contained but $9^{\circ} 6$ per cent.

It will simplify the consideration of the chemistry of mill-products if we confine our attention mainly to the nitrogen and ash of the grain. The following diagram represents the percentages of these two substances in a series of flours and brands derived from a good sample of English soft wheat. The figures are based in great measure upon the analyses made at Rothamsted by Dr. Gilbert. The mill-products termed A, B, C, are derived mainly from the central portion of the grain, and constitute "fine flour;" D is a biscuit flour known as "tailings;" $\mathrm{E}$ is intermediate between flour and bran, and goes under the name of "middlings;" F is "coarse sharps," G "fine pollard," $\mathrm{H}$ "coarse pollard," and I "long bran." $\mathrm{K}$, or thin bran, is a product obtained in the process of decorticating wheat by attrition; while $\mathrm{L}$ is separated from the grain by moistening and then rubbing it, as in the method devised by Mège Mouriés. These two latter products may legitimately find a place in the series, since they represent the last terms as we proceed towards the outer coats of the grain.

The above table explains itself; we would remark merely that both nitrogen and ash are lowest in the four 
flours, and that the former constituent attains its maximum in $F$, the coarse sharps, and the latter in I, the long bran. In $\mathrm{K}$ and $\mathrm{L}$ both nitrogen and ash are lower, these products containing much cellulose, made up as they are in great measure of the three coats which form the pericarp of the grain. But it must not be forgotten that all the mill-products included under "bran" contain much more cellulose than is present in flour, namely:-from 7 to 15 per cent., or even more, in lieu of I per cent., or less, And it would appear that while flour contains more than 90 per cent. of its nitrogen in the form of true albuminoids or flesh-formers, in some of the brans one-third of their nitrogen is in the form of non-albuminous bodies, of no recognised value as nutrients.

We have now to secure but one more datum before we proceed to the determination of the main question before us. How much flour and how much bran will ioo parts of ordinary soft wheat yield on the ordinary system of low-milling adopted in England? As the averages from an immense number of independent estimates we may put down the flour at a total of 80 , the bran at 17 , and the loss at 3. Thus, from an economical point of view, we appear to lose $\frac{1}{5}$, or twenty per cent. of our wheat by submitting it to the numerous treatments involved in the manufacture of flour. But is this really the case? We think not. For much of the nitrogen in the rejected parts is not in the form of flesh-forming matter, and much that does so exists in the bran passes unaltered and unused through the alimentary canal, because of its close incorporation with fibre. But on the other side we must not forget that bone-forming materials are clearly deficient in wheaten flour, and that those phosphatic compounds present in bran are readily soluble to a large extent, not only in the several digestive sccretions with which they come in contact in the body, but also in pure water.

But in comparing and contrasting bread made from flour with that made from whole wheat we must consider other points. We shall find it impossible to make, by means of leaven or yeast, a light spongy loaf from whole wheat finely ground, the so-called cerealin of the bran inducing chemical changes which result in a moist, clammy, dense product. Even whole wheat merely crushed into meal, and not ground, partakes of the same clefect. Fine flour, on the other hand, yields a bread which is light enough before mastication, but which, when masticated, possesses a marked tendency to become compacted into dense lumps which may never become penetrated by the gastric and intestinal juices, and which are a frequent cause of constipation. ' Whole meal bread cannot be charged with this defect; incleed it acts medicinally as a laxative, and by reason of its mechanical texture is hurried rather too quickly along the digestive tract, so that the full virtue of such of its nutrients as are really soluble becomes in part lost. Yet there is no doubt that for many persons, especially those who have passed middle age and are engaged in sedentary occupations, whole wheaten meal in the form of bread, biscuits, scones, \&c., forms an invaluable diet.

The following analyses may present some of the foregoing statements in a clearer light and may add some additional particulars of interest. They represent, so far as a couple of sets of average results can do so, the percentage composition of ordinary white bread and of the whole meal bread made by Mesrs. Hill and Son :-

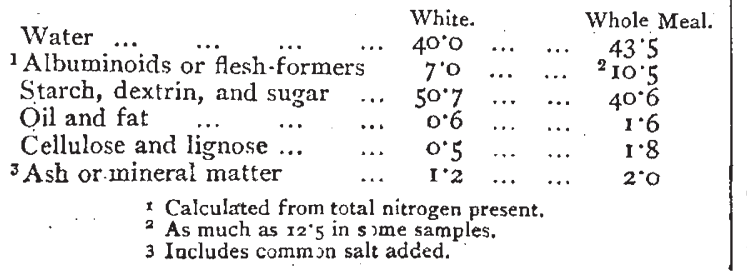

It is clear from the above figures that if we could reckon the whole of the nitrogenous matter in whole meal bread as equally effective with that contained in white bread, we should possess in the former a far more perfectly adjusted food; for the ratio of fleshformers to heat-givers is about I to $7 \frac{1}{2}$ in white bread while it approaches 1 to 4 in some samples, at least, of whole meal bread. Add to this the higher proportion of phosphates in the latter, and its chemical superiority over white bread becomes still more marked: its flavour, too, is far richer.

One word as to ordinary brown bread will suffice. It is a poor preparation at the best.. By adding a dash of rather rough bran to flour we do not obtain a satisfactory or rich product: analysis demonstrates this fact clearly.

We cannot leave this subject without referring to the little pamphlet which Messrs. Hill and Son have recently issued, 1 on the subject of wheaten meal. Though. its main purpose is necessarily a commercial one, it presents many interesting and important facts in a readable form. Messrs. Hill have certainly brought their specialty. in bread making some way on the road to perfection. With a few of the opinions in their little brochure we cannot, however, wholly concur; nor do we see how their assertion can be maintained that the present system of white bread making involves the loss of 50 to 60 per cent. of the wheat devoted to that purpose.

The limited space at our command must be our excuse for the very imperfect treatment here adopted of the wide subject before us.

\section{A. H. CHURCH}

\section{THE LAND OF BOLIVAR AND ITS PRODUCTS 2}

VENEZUELA, or the Land of Bolivar, as Mr. Spence prefers to call it, has certainly received less attention from European travellers than many other less attractive and more explored parts of South America. The Andean ranges of the north and the llanos of the south of the republic alike merit attention, and now that mining enterprise has opened up several parts of the country and tinged it with European civilisation, we know of no more come-atable country to which the naturalist could turn his steps. Certain it is that he would find ample materials for investigation, and reap a good harvest of novelties in either fauna or flora.

Mr. Spence's main object in visiting Venezuela was, as it appears, the obtaining of a concession of the privilege of working certain deposits of mineral phosphates in the Roques Islands on the northern coast of the republic. During the eighteen months occupied by the delicate negotiations required for this purpose Mr. Spence seems to have lost no time. Although nominally resident at Caracas, in order to be in immediate communication with the ministers, frequent excursions were made to the most interesting of the surrounding districts. The coal mines of Nueva Barcelona, the Lake of Valencia, and the group of islands which were the seat of the wishedfor concession, besides other localities of interest, were visited and explored. But the ascents of the Silla of Caracas and the still higher peak of Naiguata, the crowning point of the Andean range between Caracas and the coast, appears to have been the principal expeditions to which Mr. Spence devoted his attention. The first

1 "The Whole Meal Bread Question." By W. Hill and Son, Bishops. gate Street.

2"The Land of Bolivar: or, War, Peace, and Adventure in the Republic of Venezuela." By James Mudie Spence, F.R.G.S. 2 vols. 8vo. (London, 1878.)

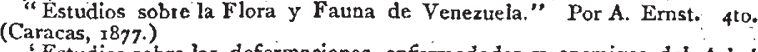

'Estudios sobre las deformaciones, enfermedades y enemigos del Arbol de Cafe en Venezuela." "Por A. Ernst. (Caracas, 1878, )

"On Venezuelan Birds Collected by Mr. A. Goeering." By P. L. Sclater, M.A., F.R.S., and Osbert Salvin, M.A., F.R.S. (Proceeding's of the Zoological Society of London, $x$ 868-75. Five articles.) 